\title{
Demand-Driven Care and Hospital Choice. Dutch Health Policy Toward Demand-Driven Care: Results from a Survey into Hospital Choice
}

\author{
Christiaan J. Lako · Pauline Rosenau
}

Published online: 19 July 2008

(C) The Author(s) 2008

\begin{abstract}
In the Netherlands, current policy opinion emphasizes demand-driven health care. Central to this model is the view, advocated by some Dutch health policy makers, that patients should be encouraged to be aware of and make use of health quality and health outcomes information in making personal health care provider choices. The success of the new health care system in the Netherlands is premised on this being the case. After a literature review and description of the new Dutch health care system, the adequacy of this demand-driven health policy is tested. The data from a July 2005, self-administered questionnaire survey of 409 patients (response rate of 94\%) as to how they choose a hospital are presented. Results indicate that most patients did not choose by actively employing available quality and outcome information. They were, rather, referred by their general practitioner. Hospital choice is highly related to the importance a patient attaches to his or her physician's opinion about a hospital. Some patients indicated that their hospital choice was affected by the reputation of the hospital, by the distance they lived from the hospital, etc. but physician's advice was, by far, the most important factor. Policy consequences are important; the assumptions underlying the demanddriven model of patient health provider choice are inadequate to explain the pattern of observed responses. An alternative, more adequate model is required, one that takes into account the patient's confidence in physician referral and advice.
\end{abstract}

Keywords Demand-driven care $\cdot$ Health policy $\cdot$ Hospital choice .

Survey

C. J. Lako (ه)

Department of Public Administration, Nijmegen School of Management, Radboud University

Nijmegen, P.O. Box 9108, 6500 HK Nijmegen, The Netherlands

e-mail: C.Lako@fm.ru.nl

P. Rosenau

Management, Policy and Community Health, School of Public Health, University of Texas,

Houston, TX, USA 


\section{Introduction}

Consumer-directed health care, consumer-driven health plans, or demand-driven care are a popular experiment in health care system reform in industrialized countries today. While the terminology may be confusing because these terms encompass several different forms of health insurance, and there are differences among them, they all share a common element. They attribute responsibility for health care choices to the patient/consumer (used interchangeably here), be it for health insurance, for physician, or for hospital services. In short, patients are expected to make informed decisions and are to be given the tools they need to do this.

Evidence about the success or failure of demand-driven care is mixed. Some report that these types of health care are a success $[53,56]$, but others deem the model as failing [23] or in need of radical revision because of low satisfaction and enrollment [14]. Some researchers report that consumer-directed plans reduce the rate of cost increases for those who select them. But evidence suggests that it is the healthiest individuals who choose these plans. Whether or not these plans will reduce costs for the general population is not known [43]. But other researchers report the opposite, that demand-driven health care is not controlling costs better than other types of organized health care systems [41]. Regarding quality, consumers were found to make both appropriate and inappropriate health care choices; some of their decisions had negative consequences for their health [2]. Maarse and TerMeulen [28] point to the various legal limits to consumer choice including high transaction costs and low administrative competence [28].

This article examines a critical aspect of demand-driven health care: whether or not individual patients will choose carefully between various health care options offered to them, if they are given the information needed to do so. In theory, providing consumers with performance data, in the form of "report cards" on provider ratings, or hospital rankings is good for individuals, providers, employers, and society [50, 65]. "The notion is that with appropriate data on quality, the consumer can 'vote' with his or her feet and choose only those health care providers that offer the best care" [10, p. 72]. The expectation seems to be that if consumers consult and act on performance data, they will "reduce their costs, improve their health status, and increase their satisfaction with medical care" [50, pp. 509-510]. Employers and society will benefit because workers will be more productive. And indeed, employers have banded together to make performance data available to their employees [15].

Several assumptions underlie this demand-driven model and evidence based on rigorous research is available as to the validity of these assumptions [64]. Much of the research about the provision and use of performance data is from the U.S. because that country has been experimenting with demand-driven, consumerdirected health care since the early 1990s as it pursues the competitive market-based model for health services.

We first examine these assumptions, summarizing the evidence available for each. Then we describe recent changes in the Dutch health system with the new emphasis on demand-driven care. After describing our study into hospital choice, 
we present new data on Dutch consumers of hospital services adding to what is already know about how consumer behavior conforms to the expectations of the demand-driven model.

The first assumption is that quality information about health plans, hospitals, and physicians actually exists. It appears that compared to fields such as automobiles and toasters, the information needed for decision making in health services is poor [45, p. 108]. In some areas, performance data is simply not available in a centralized database. Regarding hospitals, about a third of consumers report that quality ratings are simply not available for the specific hospital they seek to assess [22].

The second assumption is that performance information, if it exists, will be made available to the patient for his or her use in making health care choices. In fact 32 U.S. states require that hospitals publicize pricing information [30]. The U.S. Federal government's Centers for Medicare and Medicaid Services (CMS) now post hospital ratings. Right from the beginning of hospital certification in the U.S., JCAHO (The Joint commission on Accreditation of Healthcare Organizations) charged a fee for it [62]. This has continued to be a barrier for patients seeking quality information; fees have even increased over time [59]. Two important organizations that rate hospital performance in the U.S., NCQA (National Committee for Quality Assurance) and Healthgrades make minimal information available to consumers for free and charge several thousand dollars for detailed report cards. A "comprehensive report" is available to consumers for \$18 US [13]. The "Standard Edition was \$3,150 US— \$4,250 US in May of 2007 [37, 42]. CMS hospital data is deemed of little help to consumers because specific risk-adjusted mortality rates, while known, are omitted because they might be "misleading" to the public $[16,42]$.

Another aspect of availability relates to provider performance. And indeed, publicizing performance information encourages hospital quality improvement efforts much more than does merely collecting data for private use ([29], see for a summary of this research).

Making this information accessible to the individual patient is central to the demand-driven model, but its release has well-documented disadvantages. Ironically, perverse outcomes of lower overall population health may occur as a result of publicizing performance data. Such report cards may be used to inform consumers but they also give providers "incentives to decline to treat more difficult, severely ill patients" $[8,64]$.

The third assumption is that the form in which that information is made available is understandable and can be applied to the health care choices that the patient is called upon to make. There is evidence that quality data can be presented in a simple graphic form [47: p. 25, 52]. But in general, it is complicated information provided in a confusing array of tables. Results are often contradictory across rating systems which vary widely. For these and other reasons, patients report feeling befuddled and bewildered by performance data ([22, 33, 34], see for a summary of data on this topic [64]).

The fourth assumption is that the patient is qualified to use the performance information that is available. There is some discussion, but little actual evidence, that points to the fact that the "less articulate and demanding" patients are at a 
disadvantage as regards the ability to use performance data in making health care choices [26, 64]. The better educated are more likely to "respond to health plan report cards" [47, p. 25]. Is it the case that individuals turn to others for advice in choosing a health provider because they do not feel qualified to use performance data themselves? This is discussed below.

The fifth assumption is that the patient as consumer values the performance data. If performance is defined as simply price, then consumers have been found to use it and value it [47]. It is commonly believed that offering consumers choice makes them feel participatory, empowered, happier and more in control. But Schwartz employing experimental data finds, in several different settings, that increasing consumer choice by offering more information leads to stress and disappointment [51].

In fact, demand-driven health care models expect that price will be an important criterion in patient choice. If this were true, it might help control health care costs, but there is little evidence that, even when price is available, it is employed in choosing a hospital [59]. Still, one study found that consumers were more interested in the price and benefits package than health care performance measures [60].

If demand-driven health care is to improve quality, as well as control costs, consumers must value performance data across the board [20]. The evidence here, however, is mixed. Conversations in focus group situations found that consumers do say they want performance data [55]. Larger representative studies have confirmed this finding [22]. Nevertheless, one study reports that a large percentage of respondents did not want detailed data about providers [9]. Only about half even bothered to look at it when it was made available [50]. Some health services researchers, however, appear reluctant to report the fact that consumers may not want performance data even when it repeatedly shows up in their results [50].

The sixth assumption is that performance information is trustworthy and consumers do, in fact, trust it enough to put it to use. Trust encompasses source, method of data collection, and timeliness. Consumers in the U.S. do not trust performance data (quality indicators) in general [29]. They are especially wary of performance data that is based on self-reports by provider groups [19, p. 54]. Data presented to them by their employers is treated as suspect as well [22, 33]. Distrust is also apparent with regard to information made available via advertising, the media and by way of the government [21].

There are good reasons not to trust performance ratings in the U.S. The debate as to whether process or outcome measures are best has not been resolved. Evaluating the half dozen excellent peer-reviewed studies that have attempted to rate quality of U.S. hospitals, O'Brien and Peterson conclude: "divergence of hospital ratings is unsettlingly common" [39]. A similar conclusion was made in a Dutch study into hospital ratings [17]. One of the major providers of ranking information, JCAHO, was found in 2004 to be missing most of the safety violations in the hospitals that it monitored (69\%) [61]. In addition the performance measures employed by this widely respected agency (structure and process) are not correlated with outcomes [4, 18]. If the agencies that are counted upon to deliver quality data about hospitals are providing flawed information then it is difficult to hold consumers responsible for making informed health care choices on the basis of this information. 
Some consumers may not trust performance data or "report cards" for several additional reasons. There is a potential for conflict of interest and bias with almost all types of performance ratings [62]. Report cards are sometimes based entirely on provider self-reports. Or data may be collected and audited by agencies that charge the provider-unit for the evaluation (JACO and NCQA). In the case of HEDIS reports (prepared by NCQA) public disclosure of the final performance ratings is voluntary, not obligatory. In the late 1990 s less than $1 / 3$ of the health plans that paid to be rated on quality agreed to have their ratings made public [11]. Other research confirms this trend [31].

The seventh assumption of demand-driven health care is that the consumer does not have other criteria that substantially outweigh available, trusted, unbiased performance data [22]. The evidence suggests that consumers do have other criteria of an individual nature in mind when they choose a health provider or plan [47].

Location is an extremely important variable in determining the choice of a physician or hospital (76\%). Salisbury found that distance was the most important factor for patients in hospital choice [46]. Patients also prefer the hospital that they are "familiar with" over the hospital with a higher quality rating [22]. Some researchers suggest that even in the best of circumstances, when the medical procedure is not urgent (for example Lasik eye surgery), advice from trusted friends is given greater weight in health care decision making than performance data [1, 59]. Friends, peers, and family are preferred sources of information because performance data seems impersonal $[9,21,64]$. However, across an 8-year period, there appears to be a small trend away from consulting friends when making choices [22].

Many consumers value the advice of physicians, nurses or other health professionals more than performance report cards [22, 24]. Voelker documented the fact that patients often prefer to have their doctor choose a hospital rather than doing so themselves [62] and this is often what happens [3]. Others choose on the basis of health plan characteristics such as the size of the provider panel [5]. One study found that, when choosing a health insurance plan, emotions were much more important than reason [57].

The eight assumption is that the consumer will actually use performance data in making their health care choice. Studies of individual choice of corporate health company insurance plans or state employee health plans, across a wide range of populations, and over a decade, using a variety of methodologies, on balance, report that only a minority use the data made available to choose a plan $([6,12,25,29]$, see for a summary [64]). Consumers continue to use hospitals with high mortality rates and they appear to be influenced by anecdotal press reports of untoward deaths in hospitals rather than by risk adjusted mortality rates. When patients use performance data to select a health plan, they use it to eliminate poor performing plans rather than to choose the highest performing plans [48].

Those studies that find performance data to be extremely important for health care choices often define "performance" as price alone ([43], is an example). One study that reports the contrary, i.e. that individuals do use performance data, studied a non-representative population, federal government employees. These workers are better educated than the average U.S. citizen and would, therefore, be expected to make use of performance data at a rate greater than the general population [63]. 
One exception stands out regarding consumers' failure to employ performance data. Employers have succeeded in compelling employees to use performance data on quality when making a health plan choice, by using a financial incentive system. Employees act on quality ratings if the employer structures health insurance so that the self-pay portion of insurance is greater if the chosen plan ranks poorly on objective criteria $[15,19,33,34]$.

\section{Dutch Health Policy: The Context}

The second Balkenende Administration in the Netherlands (2003-2006) stated that health care costs had risen sharply in the last decade. It considered the supply-side system as one of the causes of the rise. They agreed that it lead to lower accessibility and a lower quality of care. Supply-side health care refers to the idea that the suppliers (providers, government, or managed-care insurers) control health care resources and have great influence in the distribution of health services.

On January 1, 2006, the three-tiered mix of public and private health insurance in the Netherlands was replaced by a new, free-market- health-insurance system. The Health Insurance Act (Zorgverzekeringswet) is grounded on a demand-driven health care system model. Health services are distributed and paid for through competitive, market-based mechanisms. The government no longer sponsors health insurance. Overall the new health insurance system reduces physician practice autonomy as it attempts to make all health providers compete on cost and quality [44, 58].

The 2006 Health Insurance Act is ground on the demand-driven health care model. Insurance companies are no longer required to contract with all providers but they are rather, encouraged to choose on the basis of negotiated arrangements with the providers they determine to be the lowest cost and the best quality. The public release of performance data in the form of quality and outcomes information about providers and hospitals is part of this model. The use of this information by patients in their decision making process is deemed essential to its success.

\section{Hospital Choice: The Study}

Expecting consumers to employ performance rating information is aligned with social science theories that emphasize rational argument as essential to consumer thinking [7, 36]. Not all theorists agree however. Some argue the opposite, that information is not very important $[27,57]$. In health care, we see representatives of both schools. Some contend that public information about access might be important in hospital choice [35], though this has not been entirely supported by research [32]. In this article, we continue the investigation as to whether or not patients make an active choice for hospital care.

From these competing theories we derive two hypotheses: one about the function of information and the other about the role of admitting physicians. One study provides evidence bearing on these hypotheses. Taken together it tests whether 
information about consumer choice, as self-reported by Dutch patients is employed in a situation where they must decide on hospital care.

\section{Hypothesis 1}

Most consumers do make an active choice for a hospital. They may be motivated by quality, access or location.

\section{Hypothesis 2}

Most consumers do not make an active choice of hospital but rather report that they are referred by their general practitioner.

\section{Methods}

Questionnaire

Patients with non-acute ailments visiting the hospital clinics of the departments of surgery, dermatology, and gynaecology of Radboud University Nijmegen Medical Centre were asked to fill out a short, self-administered questionnaire about hospital choice. They were asked: 'Why did you come with your medical problems to the Radboud University Nijmegen Medical Centre?' This hospital is associated with a medical school and is located in Nijmegen, 130 kilometres east of Rotterdam, near the Dutch-German border.

Respondents were queried about their general practitioner opinion of the hospital, about that individual as a source of information, and about their opinion of competition between hospitals. They were also asked about the details of their decision making process, especially regarding sources consulted before coming to the hospital. Patients were surveyed about the importance they attached to different types of information. A distinction was made between information about access, information about the professional skills of doctors working in the hospital, and information about the location of the hospital. Information about several socio-demographic variables was included in the questionnaire, including age, education level, etc.

\section{Sample}

In the Nijmegen area there are several hospitals including the Radboud University Medical Centre (a university-based hospital). In July 2005, a sample was drawn from patients who were seeking out-patient care from hospital-based clinics. Some sought screening or testing that was too complicated to be performed in a doctor's office. Others were at the hospital for outpatient procedures. It was a convenience sample.

A total of 409 patients visiting the specified hospital clinics were included in the sample and were questioned as to hospital choice. The response rate was an 
Table 1 Hospital choice of the patients according to their department (in percent; $n=384)$

\begin{tabular}{lcccr}
\hline & Gynaecology & Surgery & Dermatology & Total \\
\hline Referred & 58 & 73 & 76 & 69 \\
Reputation & 18 & 14 & 8 & 14 \\
Otherwise & 24 & 13 & 16 & 17 \\
Total & 100 & 100 & 100 & 100 \\
\hline
\end{tabular}

impressive 94\% $(n=384)$. The sample was representative of the Dutch population visiting a hospital in 2004 except for age; not surprisingly, those less than 20 years of age were under-represented.

Data-analysis

Data were analyzed with SPSS using $\chi^{2}$. Discriminant function analysis was performed to detect differences between patients who said that they were referred by the general practitioner and those who mentioned hospital reputation as the main reason for their hospital choice. Discriminant function analysis is a multivariate technique. It is very appropriate for our design.

\section{Results}

Most of the patients in our study state that they were referred to the hospital by their general practitioner $(69 \%)$. The remaining $31 \%$ made their own decision and obtained a letter for referral to the hospital of their choice.

The reputation of the hospital was mentioned by $14 \%$ of the interviewees as the main basis for their choice. Other elements, including the location of the hospital, were mentioned by the remaining $17 \%$ of the sample. Gynaecology patients were less likely than other patients to mention the role of the general practitioner in their decision (Table 1). However, the reputation of the hospital is mentioned more often by the gynaecology patients than by the others $\left(\chi^{2}=13.8, d f=4, p \leq 0.01\right)$.

From Table 2 it appears that fewer gynaecological department patients consider the opinion of the general practitioner as "very important" compared to patients in other departments $\left(\chi^{2}=14.7, d f=4, p \leq 0.01\right)$. Our study does not provide any additional information, but this trend might be due to the fact that many gynaecology patients were seeking care regarding childbirth delivery or fertility treatment. These may be areas of health care that permit greater conscious attention to choice.

Table 2 The importance patients attach to the physician's opinion according to their department (in percent; $n=384$ )

\begin{tabular}{lcccc}
\hline & Gynaecology & Surgery & Dermatology & Total \\
\hline Not important & 25 & 21 & 24 & 23 \\
Somewhat important & 55 & 41 & 36 & 45 \\
Very important & 20 & 38 & 40 & 32 \\
Total & 100 & 100 & 100 & 100 \\
\hline
\end{tabular}


Table 3 Hospital choice of the patients according to their education level (in percent; $n=384)$

\begin{tabular}{lcrrcr}
\hline & I (low) & II & III & IV (high) & Total \\
\hline Referred & 82 & 66 & 64 & 62 & 69 \\
Reputation & 9 & 18 & 16 & 8 & 14 \\
Otherwise & 9 & 16 & 20 & 30 & 17 \\
Total & 100 & 100 & 100 & 100 & 100 \\
\hline
\end{tabular}

One of the goals in this study also was to determine whether more highly educated patients make more active choices than less educated patients. Table 3 suggests that this is the case, better educated patients appear to be more likely than those with less education to actively choose their hospital because of its reputation or for other reasons unrelated to their physician's recommendation $\left(\chi^{2}=17.4\right.$, $d f=6, p \leq 0.01)$.

An education effect was also observed with respect to a more direct question regarding the role of the physician's opinion in hospital choice. The general practitioner's role in choice was not reported to be as important as other variables for those with more education. The data presented in Table 4 confirm that more highly educated patients attach less importance to the opinion of the general practitioner than less educated patients $\left(\chi^{2}=14.9, d f=6, p \leq 0.01\right)$.

Elderly patients were much more likely than younger patients to say that they were referred by their general practitioner $\left(\chi^{2}=12.9, d f=6, p \leq 0.01\right)$ [table not shown]. Patients reported that information about the professional skills of physicians practicing at a hospital was considered "very important" in making hospital choice (91\%). Information about access was considered "very important" by $49 \%$ of the patients whereas only $20 \%$ considered location of the hospital "very important."

Statistical associations are sometimes affected by third variables. Discriminant function analysis was employed to study whether the education effect remained in a multivariate design. Two categories of patients were involved in the analysis: patients stating that they were referred by the general practitioner and patients who mentioned that the reputation of the hospital was the main argument for their hospital choice. The discriminant function analysis included the following variables: age, education level, department, the opinion of the general practitioner about the hospital, the opinion about the general practitioner as a source of information, and opinion about competition between hospitals.

The discriminant function analysis (table not shown) demonstrated that the education effect as well as the department effect disappears while the opinions of the general practitioner about the hospital, as well as his or her role as a source of

Table 4 The importance patients attach to the physician's opinion about the hospital according to their education level (in percent; $n=384$ )

\begin{tabular}{lccccc}
\hline & I (low) & II & III & IV (high) & Total \\
\hline Not important & 17 & 25 & 26 & 23 & 23 \\
Somewhat important & 32 & 47 & 49 & 50 & 45 \\
Very important & 51 & 28 & 25 & 27 & 32 \\
Total & 100 & 100 & 100 & 100 & 100 \\
\hline
\end{tabular}


information, are critical. These two variables discriminate between the two categories of patients. The opinion of the referring physician is much more important than any other factor.

\section{Discussion}

Hypothesis 1 involves several implicit assumptions related to the new health insurance system in the Netherlands. This health insurance reform sought to transform patients into independent consumers. Today patients are encouraged to consult databases to learn about hospital performance before making a choice of a hospital. It is hoped that these consumers will take this performance information about hospitals to their primary care physician and discuss it.

On the basis of our data, we can clearly reject Hypothesis 1, and the assumption that patients in the Netherlands are rational consumers. In the real world of hospital choice, most patients in our study did not make an active hospital selection. Seven out of ten patients reported that they were simply and clearly referred by their general practitioner. In the Netherlands, the primary care doctors do not have an incentive to refer patients to a specific hospital as is sometimes the case in the United States where 'preferred provider' and HMO's negotiate discounted services and physicians are grouped by insurance companies into 'in network' or 'out of network' providers.

We used a sample of patient with non-acute ailments to prevent a strong selection-bias. The doctor is free in his or her choice, but his or her final choice may be influenced by several factors, which vary from patient to patient and from one disease to another. In some cases, a patient may be referred to a hospital clinic by a doctor other than the primary care physician, such as, for example, an occupational health physician. In some cases, patients may bypass their primary care doctor altogether and self-refer to a hospital clinic though this is not a common occurrence.

Our results are strikingly similar to a recent study reporting that $67 \%$ of the Dutch consumers rely on their general practitioner to refer them [38].

While many respondents in our study may have had specific preconceived ideas about the various hospitals available to them, in the end they deferred to their general practitioner when it came down to making a specific choice. This supports Hypothesis 2 and is in line with numerous studies reported in the above literature review, most especially that of Isaacs [21].

While highly educated patients appear to be more likely than those with less education to make active choices of hospital care, our discriminate function analysis indicates that this is not the case. The admitting physician is, in fact, the most important factor in the decision making process across all patient-education categories. This supports the findings reported by [3], summarized in our literature review.

\section{Conclusion}

On balance and in summarizing the literature above, we conclude that important assumptions required by the demand-driven models about how patients use performance data are questionable. Performance data does not always exist. Even 
when it exists, information on price and the benefits package is more widely available to patients than is information about satisfaction and quality [50]. In the U.S., high quality, detailed performance data is not only expensive to collect but, for the most, part it is made available only to consumers (mostly employers) who are willing to pay a substantial fee to have access to it. While making performance data publicly available is required by the assumptions of demand-driven health care, public disclosure has substantial, well documented, negative consequences that must be taken into account. When data is made available, it is not always easy for patients to understand it and patients sometimes do not feel qualified to use it. The relationship between availability of health care performance data and patient satisfaction is weak at best. The absence of this expected correlation is difficult to explain [19, p. 54]. While in focus groups and surveys many patients say that they want performance data, this is no guarantee that they will use it [5]. Many consumers do not trust performance data and there appear to be good reasons not to do so. Many patients prefer the advice of friends, family, or physicians over performance data. In the end, study after study reports that only a minority of patients use performance data in making health care choices.

This study clearly demonstrates that policy makers, those who designed the new Dutch health care system, should not count on demand-driven health care succeeding if it depends on active consumers consulting performance data and then acting upon that information to choose a hospital when in need of hospital services. To assume that this is the case is unrealistic. Hospital choice, at least in those countries studied to date, and in the Netherlands, seems to be a decision making process that is heavily dependent on general practitioners playing an important role in this process.

This and other evidence is, indeed, beginning to be addressed by policy-makers. Now that the gap between the assumptions of demand-driven health care and reality is recognized, measures are being proposed to deal with it. Some suggest that the answer is to educate patients as to how to shop for health care and use performance data [59]. However, our multivariate analysis found that education alone does not mold patients into rational consumers. If that were true, we would likely see that the highly educated would already be rational, individual consumers and that is not the case. Policy makers might want to consider another option. Asking physicians and health care providers to use the performance data, rather than relying on consumers to employ it, might be a better policy alternative in light of the evidence. This would mean shifting from a demand-driven model to a responsible provider model.

Every empirical study involves limitations as does this study. Caution with respect to results is usually warranted. Some caution with the results is needed. The sample does not represent all Dutch patients visiting a hospital since younger people are somewhat under-represented in this study. Data collection via a selfadministered questionnaire is assumed to have resulted in less bias. The risk of social desirability in answering questions has been reduced by the utilization of this type of self-administered questionnaire. In person, one-on-one interviews with patients would probably have resulted in more social desirability effects. One might also ask whether or not patients in a university hospital were likely to have been 
referred by a clinician from another hospital, but we sampled patients with nonacute ailments to reduce this bias.

The hospital studied, The Radboud University Medical Centre, is the only university-based hospital in this area. Had our study been undertaken in another region, for example Amsterdam, where there is more competition for patients among both university hospitals, the results might have been different. However, there is no reason, a priori, to believe this is the case. In geographical areas where hospital choice is greater and the market more competitive, it might be that patients would be more critical shoppers for hospital services. But it is also possible that they would be even more inclined to look to their primary care doctor for guidance. This is a topic in need of further research.

Acknowledgements The clinicians and nurses of the departments in this study are kindly acknowledged for their contribution to the collection of the data. Claudine Coenen is kindly acknowledged for the collection of the data.

Open Access This article is distributed under the terms of the Creative Commons Attribution Noncommercial License which permits any noncommercial use, distribution, and reproduction in any medium, provided the original author(s) and source are credited.

\section{Appendix}

Questionnaire Hospital Choice

1. What is your age? ...years

2. What is your education?

1. Lagere school (low)

2. $\mathrm{LBO}$

3. MAVO

4. $\mathrm{MBO}$

5. $\mathrm{HBO}$

6. HAVO

7. VWO

8. Universiteit (high)

3. Why did you come with your medical problems to the Radboud University Medical Centre?

1. Referred by my General Practitioner

2. The hospital is close to my home

3. The reputation of the hospital

4. Other: ....

4. What do you consider important when choosing a hospital? (not important-somewhat important-very important)

1. The opinion of my General Practitioner about the hospital

2. The location of the hospital close to my home 
3. The reputation of the hospital

4. The expected waiting time

5. Others:.........

5. Which information source do you employ when choosing a hospital?

1. Information from the General Practitioner

2. Information from Internet

3. Information from friends or relatives

4. I do not use any information

5. Others:....

6. What kind of information do you consider important when choosing a hospital? (not important-somewhat important-very important)

1. Information about the expected waiting time

2. Information about the professional skills of the physicians

3. Information about the location of the hospital

4. Others: ...

7. What do you think about competition between hospitals?

1. No opinion

2. Good

3. $\mathrm{Bad}$

4. Neutral

8. What do you consider important when choosing a health plan?

(not important-somewhat important-very important)

1. The premium

2. Additional supplementary coverage

3. The reputation of the health plan

4. The insurance company providing me access to hospitals and health services

9. Do you consider expected waiting times of 7 weeks (maximum) in hospitals for non-acute ailments as a problem?

1. Yes

2. No

\section{References}

1. Bates, D. W. (2000). The impact of the Internet on quality measurement. Health Affairs-Web Exclusive, 19(6), 104-114.

2. Buntin, M. B., Damberg, C., Haviland, A., Kapur, K., Lurie, N., McDevitt, R., et al. (2006). Consumer-directed health care: Early evidence about effects on cost and quality. Health Affairs-Web Exclusive, 25(6), w516-w530. 
3. Burns, L. R., \& Wholey, D. R. (1992). The impact of physician characteristics in hospital choice; models for hospital care. Journal of Health Economics, 11, 43-62.

4. Chen, J., Rathore, S. S., Radford, M. J., \& Krumholz, H. M. (2003). JCAHO accreditation and quality of care for acute myocardial infarction. Health Affairs, 22(2), 243-254.

5. Chernew, M., \& Scanlon, D. P. (1998). Health plan report cards and insurance choice. Inquiry, 35, 922.

6. Christianson, J., Parente, S., \& Feldman, R. (2004). Consumer experiences in a consumer driven health plan. Health Services Research, 39(4 Pt 2), 1123-1140.

7. Downs, A. (1967). Inside bureaucracy. Boston: Brown and Company.

8. Dranove, D., Kessler, D., McClellan, M., \& Satterthwaite, M. (2003). Is more information better? The effects of 'report cards' on health care providers. Journal of Political Economy, 111(3), 555-588.

9. Edgman-Levitan, S., \& Cleary, P. (1996). What information do consumers want and need? Health Affairs-Web Exclusive, 15(4), 42-56.

10. Editor. (2003). Public reporting of health quality information. Health Affairs, 22(2), 72.

11. Farley, D. O., Farley Short, P., Elliott, M. N., Kanouse, D. E., Brown, J. A., \& Hays, R. D. (2002). Effects of CAHPS health plan performance information on plan choices by New Jersey Medicaid beneficiaries. Health Services Research, 37(4), 985-1007.

12. Farley, D. O., McGlynn, E., \& Klein, D. (1998). Assessing quality in managed care: Health plans reporting of HEDIS performances measures. New York, NY: The Commonwealth Fund.

13. Francis, T. (2007, July 10). How to size up your hospital: Improved public databases let people compare practices and outcomes; The importance of looking past the numbers. Wall Street Journal, p. D1.

14. Fuhrmans, V. (2007, June 12). Health savings plans start to falter. The Wall Street Journal.

15. Galvin R. S., Delbanco S., Milstein A., \& Belden, G. (2005). Has the Leapfrog group had an impact on the health care market? Health Affairs, 24(1), 228-233.

16. Gerber, M. S. (2007, July 3). Hospitals are beyond compare. Washington Post.

17. Giard, R. W. M. (2006). Ziekenhuistop-100: Wisselende ranglijsten, wisselende reputaties. Nederlands Tijdschrift voor Geneeskunde, (Dutch Journal of Medicine), 150(43), 2355-2358.

18. Griffith, J. R., Knutzen, S. R., \& Alexander, J. A. (2002). Structural versus outcomes measures in hospitals: A comparison of joint commission and Medicare outcomes scores in hospitals. Quality Management in Health Care, 10(2), 29-38.

19. Haas-Wilson, D. (2003). The antitrust challenge. Cambridge, MA: Harvard University Press.

20. Hibbard, J. H., Slovic, P., \& Jewett, J. J. (1997). Informing consumer decisions in health care: Implications from decision-making research. Milbank Quarterly, 75(3), 395-414.

21. Isaacs, S. L. (1996). Consumer's information needs: Results of a national survey. Health Affairs, 15(4), 31-41.

22. Kaiser Family Foundation, Agency for Healthcare Research and Quality, \& Harvard School of Public Health. (2004). National Survey on Consumers' Experiences with Patient Safety and Quality Information: Kaiser Family Foundation.

23. Kelly, S. (2007, June 1). Biz fails to sell merits of consumer health. Financial Week.

24. Kenis, P. (2001). Die wachtlijsten is een verhaal apart. Een organisatiewetenschappelijke beschouwing van het fenomeen wachtlijst in de Nederlandse zorg: Tilburg.

25. Knutson, D. J., Kind, E. A., Fowles, J. B., \& Adlis, S. (1998). Impact of report cards on employees: A natural experiment. Health Care Financing Review, 20(1), 5-27.

26. Light, D. W. (2006). Allyson M. Pollock. NHS plc: The privatisation of our health care. Journal of Health Politics, Policy and Law, 31(6), 1158-1163.

27. Lindblom, C. E. (1959). The science of muddling through. Public Administration Review, 19, 78-88.

28. Maarse, H., \& ter Meulen, R. (2006). Consumer choice in Dutch health insurance after reform. Health Care Analysis, 14, 37-49.

29. Marshall, M. N., Shekelle, P. G., Leatherman, S., \& Brook, R. H. (2000). The public release of performance data: What do we expect to gain? The Journal of the American Medical Association, 283(14), 1866-1874.

30. Mason, M. (2007, February 27). Bargaining down that CT scan is suddenly possible. New York Times, p. D5.

31. McCormick, D., Himmelstein, D., Woolhandler, S., Wolfe, S., \& Bor, D. (2002). Relationship between low quality-of-care scores and HMOs' subsequent policy disclosure of quality-of-care scores. The Journal of the American Medical Association, 288, 1484-1490.

32. Meijer, A. (2004). Vreemde ogen dwingen. De betekenis van internet voor maatschappelijke controle in de publieke sector: Den Haag. 
33. Meyer, J. A., Wicks, E. K., Rybowski, L. S., \& Perry, M. J. (1998). Report on report cards. Washington D.C.: Economic and Social Research Institute.

34. Meyer, J. A., Wicks, E. K., Rybowski, L. S., Perry, M. J., Bagby, N. S., Rosenberg, L. E., et al. (1998). Report on Report Cards: Initiatives of Health Coalitions and State Government Employers to Report on Health Plan Performance and Use Financial Incentives (Executive Summary): Economic and Social Research Institute in collaboration with Midwest Business Group on Health.

35. Ministerie van V.W.S. (2001). Vraag aan bod. Hoofdlijnen van vernieuwing van het zorgstelsel: Den Haag.

36. Mueller, D. C. (1989). Public choice II: A revised edition of public choice (2 ed.). Cambridge: Cambridge University Press.

37. NCQA-National Committee for Quality Assurance. (2007). HEDIS 2008 Package \$965.00. Retrieved June 7, 2007, 2007, from https://inetshop01.pub.ncqa.org/publications/product.asp? dept $\% 5$ Fid $=2 \& p f \% 5$ Fid=10283\%2D150\%2D08.

38. Nederlandse Zorgautoriteit (Dutch Healthcare Authority) (NZa). (2007). Richting geven aan keuzes. Kunnen verzekeraars consumenten stimuleren naar gecontracteerde voorkeursaanbieders te gaan? (Influencing Choices: Can Health Insurers Encourage Consumers to Go to Preferred Providers?): Nederlandse Zorgautoriteit (Dutch Healthcare Authority) (NZa).

39. O'Brien, S. M., \& Peterson, E. D. (2007). Identifying high-quality hospitals: Consult the ratings or flip a coin? Archives of Internal Medicine, 167(13), 1342-1344.

40. Oliver, A. (2005). The English National Health Service: 1979-2005. Health Economics, 14, S75-S99.

41. Parente, S. T., Feldman, R., \& Christianson, J. (2004). Evaluation of the effect of a consumer-driven health plan on medical care expenditures and utilization. Health Services Research, 39(4 Part 2), 1189-1209.

42. Pearlstein, S. (2007, April 20). Hospitals check their charts. The Washington Post, pp. D01-D03.

43. RAND. (2007). Consumer-Directed Health Care: Early Evidence Shows Lower Costs, Mixed Effects on Quality of Care (Research Highlights from Health Affairs web exclusive January 29 2007, pp. w516-w530). Santa Monica, CA: RAND Corporation.

44. Rosenau, P. V., \& Lako, C. (2007). Can "regulated competition" for health insurance control health care costs, preserve access, and serve society? The new Dutch health system. In C. Lako (Ed.), Annual meeting of the American public health association. Washington DC: American Public Health Association.

45. Sage, W. (2003). Interview: Protecting competition and consumers: A conversation with Timothy J. Muris. Health Affairs, 22, 101-110.

46. Salisbury, C. J. (1989). How do people choose their doctor? British Medical Journal, 299, 608-610.

47. Scanlon, D. P., Chernew, M., McLaughlin, C., \& Solon, G. (2002). The impact of health plan report cards on managed care enrollment. Journal of Health Economies, 21, 19-41.

48. Schauffler, H. H., \& Mordavsky, J. K. (2001). Consumer reports in health care: Do they make a difference? Annual Review of Public Health, 22(1), 69.

49. Schneider, E., \& Epstein, A. (1996). Influence of cardiac-surgery performance reports on referral practices and access to care. New England Journal of Medicine, 335, 251-256.

50. Schultz, K. T. C., Feldman, R., \& Christianson, J. (2001). Do employees use report cards to assess health care provider systems? Health Services Research, 36.3, 509.

51. Schwartz, B. (2005). The paradox of choice: Why more is less. New York: Harper Collins.

52. Shaller, D., Sofaer, S., Findlay, S. D., Hibbard, J. H., Lansky, D., \& Delbanco, S. (2003). Consumers and quality-driven health care: A call to action. Health Affairs, 22(2), 95-101.

53. Sharon, C. W., \& Donahue, T. (2006). Lessons from the first five years. Benefits Quarterly, 22(2), $15-22$.

54. Simon, H. A. (1947). Administrative behavior: A study of decision making processes in administrative organization. New York/London.

55. Sofaer, S., Crofton, C., Goldstein, E., Hoy, E., \& Crabb, J. (2005). What do consumers want to know about the quality of care in hospitals. Health Services Research, 40(6p2), 2018-2036.

56. Sullivan, P. E. Jr., \& Sharon, C. W. (2006). Consumer-Driven Health Plans Gaining Stronger Presence: Aon Consulting/ISCEBS Survey Findings.

57. Towers-Perrin. (2005). Despite years of education, employees continue to buy health coverage with their hearts not their heads, towers Perrin finds. Retrieved June 14, 2005, from http://www.insurance-canada.ca/market/other/Towers-Perrin-Employees-Health-507.php.

58. Trappenburg, M. (2005). Fighting sectional interest in health care. Health Care Analysis, 13(3), 223237. 
59. Tu, H. T., \& May, J. (2007). Self-pay markets in health care: Consumer nirvana or caveat emptor? Health Affairs-Web Exclusive, 26(2), w217-w226.

60. Tumlinson, A., Bottigheimer, H., Mahoney, P., Stone, E., \& Hendricks, A. (1997). Choosing a health plan: What information will consumers use? Health Affairs, 16, 229-238.

61. U.S. General Accountability Office. (2004). Medicare: CMS needs additional authority to adequately oversee patient safety in hospitals (No. GAO-04-850). Washington: U.S. General Accounting Office.

62. Voelker, R. (1995). Why has 'historic' public disclosure of hospital performance data attracted so little attention? The Journal of the American Medical Association, 273(9), 689-690.

63. Wedig, G. J., \& Tai-Seale, M. (2002). The effect of report cards on consumer choice in the health insurance market. Journal of Health Economies, 21, 1031-1048.

64. Werner, R. M., \& Asch, D. A. (2005). The unintended consequences of publicly reporting quality information. The Journal of the American Medical Association, 293(10), 1239-1244.

65. Wilmot, S. (2007). A fair range of choice: Justifying maximum patient choice in the British National Health Service. Health Care Analysis, 15, 59-72. 